\title{
Perspectivas geográficas nas TRANSFORMAÇÕES DO LITORAL BRASILEIRO PELA ENERGIA EÓLICA
}

\author{
Christian Brannstrom ${ }^{1,2}$; Adryane Gorayeb ${ }^{2}$; Wallason Farias de Souza'; Nicolly Santos \\ Leite $^{2}$; Leilane Oliveira Chaves ${ }^{3}$; Rodrigo Guimarães ${ }^{4}$; Dweynny Rodrigues Filgueira Gê ${ }^{4}$ \\ 1. Departamento de Geografia, Texas A\&M University \\ 2. Programa de Pós-Graduação em Geografia, Universidade Federal do Ceará \\ 3. Programa de Pós-Graduação em Desenvolvimento e Meio Ambiente, Universidade Federal do Ceará \\ 4. Programa de Pós-Graduação em Ciências Naturais, Universidade Estadual do Rio Grande do Norte
}

\section{Resumo}

A implantação da energia eólica está transformando as condições socioambientais no litoral brasileiro, especialmente no Nordeste. Para aprofundar o tema, usamos análise espacial em Sistema de Informação Geográfico - SIG para demonstrar que quase $50 \%$ dos aerogeradores do Rio Grande do Norte e do Ceará estão localizados em até $5 \mathrm{~km}$ de distância da costa. Através de estudo de campo em seis casos específicos, demonstramos por quê existem conflitos entre as comunidades e os empreendimentos e, por outro lado, quais os principais fatores que causam boas relações entre as empresas de energia e as comunidades.

Palavras-chave: energia eólica; litoral; comunidade; conflito.

\begin{abstract}
The development of wind power is transforming socioenvironmental conditions in Brazil's coastline, especially in the northeast. To investigate this issue, we performed spatial analysis in a Geographic Information System (GIS) to demonstrate that nearly $50 \%$ of the wind turbines in Rio Grande do Norte and Ceará are located within $5 \mathrm{~km}$ of the shoreline. Field work in six sites demonstrates why conflicts exist between communities and wind farms and, on the other hand, which are the main factors that create good relations between wind firms and communities.
\end{abstract}

Key words: wind power; coast; community; conflict.

$\mathrm{O}$ crescimento rápido da energia eólica no Brasil é, em grande parte, um fenômeno costeiro, já que $46 \%$ das turbinas eólicas estão localizadas na faixa até $25 \mathrm{~km}$ de distância do litoral e $26 \%$ distam até $5 \mathrm{~km}$ da costa brasileira. No Ceará e no Rio Grande do Norte, dois estados que possuem $43,8 \%$ de capacidade instalada de energia eólica brasileira, $43 \%$ dos aerogeradores estão localizados em até $5 \mathrm{~km}$ de distância da linha de costa. Os impactos socioambientais, destacados neste trabalho, significam um novo fator na geografia do litoral brasileiro além do turismo, da infraestrutura e da carcinicultura (MORAES, 1999). Nesse contexto, este trabalho tem por objetivos sintetizar os impactos socioambientais da energia eólica no litoral brasileiro, identificar as causas principais para as experiências negativas e positivas e compreender as principais lacunas de conhecimento para serem aprofundadas por pesquisas futuras. 
As estimativas globais de Lu et al. (2009) indicam que aerogeradores onshore com capacidade de 2,5 MW podem gerar mais de 40 vezes do consumo global atual de energia elétrica. Porém, esta conclusão não contempla os territórios onshore onde os parques eólicos seriam implementados. Scheidel e Sorman (2012) advertem que um "land grab" ou corrida pela terra poderia resultar da alta procura de vastos territórios para a implantação dos parques eólicos necessários para possibilitar o atendimento à demanda energética global. Fairhead et al. (2012) definem "green grabbing" como a apropriação de terras e recursos com finalidades ou justificativas ambientais, baseadas na "acumulação por espoliação", conceito incutido na obra do geógrafo David Harvey (HARVEY, 2003).

Na bibliografia internacional, apenas é bem estudada a localização de parques eólicos no litoral da Austrália onde, segundo Harvey et al. (2017) e Harvey e Dew (2016), 64\% dos parques eólicos e $51 \%$ da capacidade instalada estão localizados em até $25 \mathrm{~km}$ de distância da linha de costa. Os autores argumentam que o crescimento rápido da capacidade instalada ultrapassa a capacidade do estado no zoneamento territorial. Segundo Harvey et al. (2017, p. 377), existe uma política desarticulada entre os governos estaduais e o governo federal que criou um descompasso no planejamento territorial integrado.

A energia eólica brasileira é uma resposta bem-sucedida entre os setores público e privado à crise do fornecimento de eletricidade em 2001, que deu origem ao Programa de Incentivos às Fontes Alternativas de Energia (PROINFA), considerado "o incentivo primário para a energia renovável brasileira" (AQUILA et al., 2017, p. 1091). O PROINFA, junto com modificações no licenciamento ambiental, leilões para atrair investidores, conexões de rede de transmissão aos parques eólicos, crédito do BNDES, e redução nas barreiras à importação de componentes, criaram condições atraentes para investimentos em parques eólicos no Brasil (JUÁREZ et al., 2014; SILVA et al., 2016; ARAÚJO; FREITAS, 2008; FILGUEIRAS; SILVA, 2003). De fato, entre 2008 e abril de 2018, a capacidade eólica instalada no Brasil aumentou de 0,341 MW a 12,8 MW, representando um investimento de mais de US\$ 32 bilhões (ASSOCIAÇÃO BRASILEIRA DE ENERGIA EÓLICA, 2017). O Global Wind Energy Council destacou que o Brasil é o pais latino-americano com melhores condições do mercado de energia eólica onshore apesar dos desafios políticos e econômicos (GWEC, 2017).

No Brasil, a bibliografia sobre a energia eólica na perspectiva da engenharia mostra otimismo quanto ao potencial energético, especialmente no Nordeste, devido à complementariedade entre a geração hidrelétrica, a alta qualidade do recurso eólico e a alta eficiência dos aerogeradores, na atração de investimentos necessários para aumentar a capacidade instalada (SILVA et al., 2016; JUÁREZ et al., 2014; AQUILA et al., 2017; DE JONG et al., 2016). Segundo estimativas, a energia eólica representa o menor custo por megawatt considerando os custos de transmissão e os impactos ambientais de outras formas de gerar energia elétrica (DE JONG et al., 2015). Previsões indicam que a energia eólica pode atender a $57 \%$ da demanda da eletricidade no Nordeste brasileiro, representando uma maneira de poupar a vazão do Rio São Francisco, especialmente no final da estação seca (DE JONG et al., 2017).

Estudos geográficos sobre o litoral brasileiro apontam diversos impactos, como o turismo, urbanização, extração de petróleo e maricultura (MORAES, 1999; JABLONSKI; FILET, 2008; MARRONI; ASMUS, 2013; QUIEROZ et al., 2013), porém é recente a observação de que a energia eólica gera impactos socioambientais sobre o litoral. Por exemplo, Carvalho e Silva (2015, p. 
10), na sua síntese de questões ambientais no litoral nordestino, indicaram a "expansão dos parques eólicos sobre campos de dunas e próximos a lagoas e faixas de praia" como um problema emergente. Desde 2008, são identificados problemas ambientais e sociais devido à implantação de parques eólicos no litoral do estado do Ceará, onde o problema fundamental é a localização dos parques, uma vez que a maioria está na faixa costeira, em ambientes de dunas, praias, manguezais e lagoas que são ocupados, secularmente, por comunidades tradicionais "invisibilizadas" (MEIRELES, 2011). Conforme Leroy e Meireles (2013, p. 129) "As poderosas coalizões, que buscam eliminar do mapa ou reduzir a reservas (as menores possíveis) de povos indígenas e comunidades tradicionais, parecem considerá-los elementos sobreviventes do passado, arcaicos obstáculos ao progresso".

Os processos de engenharia que são realizados para possibilitar a implantação dos parques eólicos apresentam fases que culminam em impactos negativos para o meio ambiente, por meio de desmatamentos da vegetação nativa, soterramentos de lagoas naturais, aplainamentos de dunas, modificação das propriedades dos solos e alteração das dinâmicas naturais dos fluxos litorâneos. Os impactos sociais envolvem mudanças na segurança alimentar dos povos tradicionais costeiros, a partir da diminuição das áreas de extrativismo vegetal e animal, devido às alterações nos ecossistemas litorâneos, diminuição das áreas agricultáveis, devido à perda de territórios de uso comum para os parques eólicos, que bloqueiam a entrada dos moradores e, em geral, não permitem atividades conjugadas (como a de pastoreio, por exemplo), diminuição da pesca, especialmente a continental, devido à alteração do fluxo de sedimentos litorâneos e o aterramento de lagoas, fato que ocorre comumente durante a construção dos parques eólicos em ambiente de praias e dunas (MEIRELES, 2011; BROWN, 2011; MEIRELES et al., 2013, 2015; ARAÚJO, 2015; GORAYEB et al., 2016).

Outros impactos dizem respeito ao bloqueio aos acessos à praia e às localidades vizinhas, o que cerceia o direito de mobilidade dos moradores locais, que ficam impedidos de transitar livremente por seus territórios; a mudança brusca na rotina das comunidades, com a entrada de grande quantidade de trabalhadores de outras regiões, mudando a rotina dos habitantes locais e impactando, muitas vezes, de forma negativa na vida social, a partir da entrada de maiores quantidades de bebidas alcoólicas, drogas ilícitas e, até mesmo, relatos de prostituição infantil e gravidez precoce, com o nascimento de crianças que ficam conhecidas nas comunidades como "filhos do vento" (GORAYEB et al., 2018).

Destacamos que o favorecimento da ocupação das áreas costeiras, por meio do licenciamento ambiental simplificado, tem colaborado na associação de investidores com as elites locais na aquisição de terrenos para a construção dos parques eólicos (GORAYEB; BRANNSTROM, 2016; GORAYEB et al., 2018) muitas vezes de forma obscura e ilegal e, ao mesmo tempo, provocado a insegurança fundiária das comunidades (BRANNSTROM et al., 2017), já que nessas localidades há uma expressiva quantidade de residentes tradicionais que utilizam os recursos presentes no território para a sua reprodução sociocultural e econômica.

Para entender os vários casos de oposição à energia eólica, principalmente na América do Norte e na Europa, a bibliografia internacional se concentra no "social gap" ou desencontro social, definido como a diferença entre a opinião pública nacional favorável à energia eólica em contradição com a oposição local o que, muitas vezes, resultou em projetos cancelados nos países do Norte (BELL et al., 2005; BELL et al., 2013). Os vários estudos de caso sobre o "social gap" da 
energia eólica (e as energias renováveis de forma geral) foram sintetizados com uma visão global por Sovacool (2009), Sovacool e Ratan (2012) e, especificamente para os Estados Unidos por Rand e Hoen (2017) e para o Canadá por Fast et al. (2017).

Uma vertente do "social gap" é a ideia de que a "imposição" da energia eólica sem compensação ou mitigação dos efeitos negativos pode causar conflitos entre as pessoas e os investidores, pela crença que os projetos são desenvolvidos por estranhos, para benefícios de terceiros (PASQUALETTI, 2011). A "imposição" é resultado das práticas de empreendedores e planejadores que priorizam questões técnicas de eficiência e qualidade do vento acima das considerações sociais, culturais e simbólicas dos territórios onde os parques se instalam, como o apego humano ao local, a identidade com a paisagem e a interrupção dos meios de subsistência baseados em recursos naturais. Outra vertente complementar entende que embora possam haver múltiplos fatores para explicar o "social gap", os aspectos referentes ao nível de participação local na evolução do projeto e como são distribuídos custos e/ou benefícios podem ser determinantes em escala local na perspectiva da justiça participativa e distributiva (WALKER; BAXTER, 2017).

\section{Materiais e métodos}

O método para análise da distribuição espacial dos parques eólicos instalados nas proximidades da costa brasileira consistiu na integração de dados geográficos no Sistema de Informações Geográficas (SIG) free opensource QGIS, com a sobreposição das seguintes camadas de informações: (i) base vetorial da linha de costa, disponibilizada pelo Serviço Geológico do Brasil (2018) e (ii) base vetorial de dados georreferenciados das torres de aerogeradores do Brasil, disponibilizada pelo Sistema de Informações Georreferenciadas do Setor Elétrico (SIGEL), vinculado à Agência Nacional de Energia Elétrica (AGÊNCIA NACIONAL DE ENERGIA ELÉTRICA, 2018), contendo os aerogeradores em operação em março de 2018, bem como suas informações básicas (parque vinculado, altura, potência nominal e início da operação).

Esses dados foram compilados no software QGIS utilizando as ferramentas "contar pontos no polígono" e "selecionar pela localização" para analisar a distribuição espacial dos aerogeradores e a sua distância em relação à linha de costa. Foram criados buffers da linha de costa de 5, 10 e $25 \mathrm{~km}$ (onshore), permitindo identificar o posicionamento dos pontos (aerogeradores) em relação ao seu litoral mais próximo.

Os aerogeradores posicionados dentro desses buffers foram agrupados, com base na localização situacional de cada um deles em relação aos intervalos de distâncias da costa (buffers) e, posteriormente, foram somados juntamente com seu atributo de capacidade nominal para determinar a quantidade de aerogeradores e a potência instalada em cada zona. Os dados foram individualizados por Estado, gerando uma base de informações detalhadas em nível estadual, com recortes multiescalonares.

Foram feitas revisões de documentos oficiais sobre energia eólica e todos os membros da equipe autorial realizaram visitas aos parques eólicos e às comunidades afetadas entre os anos de 2016 e 2018, em uma totalidade de cerca de 20 empreendimentos. As metodologias dos trabaIhos que sintetizamos neste texto incluíram a cartografia social (GORAYEB; MEIRELES; SILVA, 
2015), aplicação de questionários usando amostragem aleatória, observação participativa com associações e lideranças comunitárias, entrevistas semiestruturadas e informais com moradores e lideranças das comunidades impactadas, e mapeamento de unidades geoecológicas dentro e vizinhas dos parques eólicos. Estas atividades já culminaram em teses e dissertações no Programa de Pós-Graduação em Geografia da Universidade Federal do Ceará.

\section{Resultados}

\section{a. Análise da localização geográfica dos aerogeradores}

Em termos nacionais, aproximadamente $46 \%$ dos aerogeradores brasileiros estão localizados em até $25 \mathrm{~km}$ de distância da linha costeira e 26\% estão situados em até $5 \mathrm{~km}$ de distância da linha de costa (Tabela 1; Tabela 2). Considerando-se os quatro estados com maior potência instalada, no Rio Grande do Norte 29\% das torres (representando 26\% da capacidade energética instalada) estão localizadas dentro da faixa de $5 \mathrm{~km}$ da linha de costa (Figura 1). No mesmo estado, 58\% de todos os aerogeradores se concentram dentro da faixa de $25 \mathrm{~km}$ de distância da linha de costa. No Ceará, 21\% dos aerogeradores estão dentro da faixa de $5 \mathrm{~km}$ da linha de costa, porém estes aerogeradores representam $68 \%$ da capacidade instalada do estado, devido ao grande porte dos empreendimentos em comparação com os parques existentes no interior (Figura 2). Na Bahia, o segundo estado brasileiro quanto à capacidade instalada, os parques eólicos estão localizados totalmente no interior. No Rio Grande do Sul, $6 \%$ dos aerogeradores estão dentro da faixa de 5 $\mathrm{km}$ da linha costeira, enquanto $62 \%$ estão entre as faixas de 5 e $25 \mathrm{~km}$.

Tabela 1. Capacidade instalada de energia eólica no litoral brasileiro, por estado

\begin{tabular}{|c|c|c|c|c|c|c|c|c|c|c|}
\hline \multirow{2}{*}{ Estado } & \multicolumn{2}{|c|}{ Até 5 km } & \multicolumn{2}{|c|}{ Entre 5 e 10 km } & \multicolumn{2}{|c|}{$\begin{array}{c}\text { Entre } 10 \text { e } 25 \\
\text { km }\end{array}$} & \multicolumn{2}{|c|}{ Mais de $25 \mathrm{~km}$} & \multicolumn{2}{|c|}{ Total } \\
\hline & MW & $\%$ & MW & $\%$ & MW & $\%$ & MW & $\%$ & MW & $\%$ \\
\hline Rio Grande do Norte & 940 & $25,8 \%$ & 319 & $8,8 \%$ & 875 & $24,0 \%$ & 1.506 & $41.4 \%$ & 3.640 & $29,4 \%$ \\
\hline Bahia & 0 & $0,0 \%$ & 0 & $0,0 \%$ & 0 & $0,0 \%$ & 2.258 & $100.0 \%$ & 2.258 & $18,2 \%$ \\
\hline Ceará & 1.222 & $68,4 \%$ & 360 & $20,2 \%$ & 51 & $2,9 \%$ & 153 & $8.6 \%$ & 1.786 & $14,4 \%$ \\
\hline Rio Grande do Sul & 401 & $21,9 \%$ & 437 & $23,8 \%$ & 717 & $39,1 \%$ & 277 & $15.1 \%$ & 1.832 & $14,8 \%$ \\
\hline Brasil & 3.021 & $24,4 \%$ & 1.126 & $9,1 \%$ & 1.643 & $13,3 \%$ & 6.585 & $53.2 \%$ & 12.375 & \\
\hline
\end{tabular}

Fonte: Sistema de Informações Georreferenciadas do Setor Elétrico (SIGEL). 
Tabela 2. Número de aerogeradores para energia eólica no litoral brasileiro, por estado

\begin{tabular}{|c|c|c|c|c|c|c|c|c|c|c|}
\hline \multirow{2}{*}{ Estado } & \multicolumn{2}{|c|}{ Até $5 \mathrm{~km}$} & \multicolumn{2}{|c|}{$\begin{array}{c}\text { Entre } 5 \text { e } 10 \\
\text { km }\end{array}$} & \multicolumn{2}{|c|}{$\begin{array}{c}\text { Entre } 10 \text { e } 25 \\
\text { km }\end{array}$} & \multicolumn{2}{|c|}{ Mais de $25 \mathrm{~km}$} & \multicolumn{2}{|c|}{ Total } \\
\hline & $\mathrm{N}^{\mathrm{o}}$ & $\%$ & $\mathrm{~N}^{\mathrm{O}}$ & $\%$ & $\mathrm{~N}^{\mathrm{o}}$ & $\%$ & $\mathrm{~N}^{\mathrm{o}}$ & $\%$ & $\mathrm{~N}^{\mathrm{o}}$ & $\%$ \\
\hline Rio Grande do Norte & 531 & $28,9 \%$ & 138 & $7,5 \%$ & 395 & $21,5 \%$ & 774 & $42.1 \%$ & 1.838 & $29,2 \%$ \\
\hline Bahia & 0 & $0,0 \%$ & 0 & $0,0 \%$ & 0 & $0,0 \%$ & 1.176 & $100.0 \%$ & 1.176 & $18,7 \%$ \\
\hline Ceará & 632 & $20,9 \%$ & 152 & $17,0 \%$ & 23 & $2,6 \%$ & 88 & $9.8 \%$ & 895 & $14,2 \%$ \\
\hline Rio Grande do Sul & 181 & $6,0 \%$ & 199 & $24,0 \%$ & 316 & $38,1 \%$ & 133 & $16.0 \%$ & 829 & $13,2 \%$ \\
\hline Brasil & 1.635 & $54,1 \%$ & 495 & $7,9 \%$ & 734 & $11,7 \%$ & 3.425 & $54.5 \%$ & 6.289 & \\
\hline
\end{tabular}

Fonte: Sistema de Informações Georreferenciadas do Setor Elétrico (SIGEL).

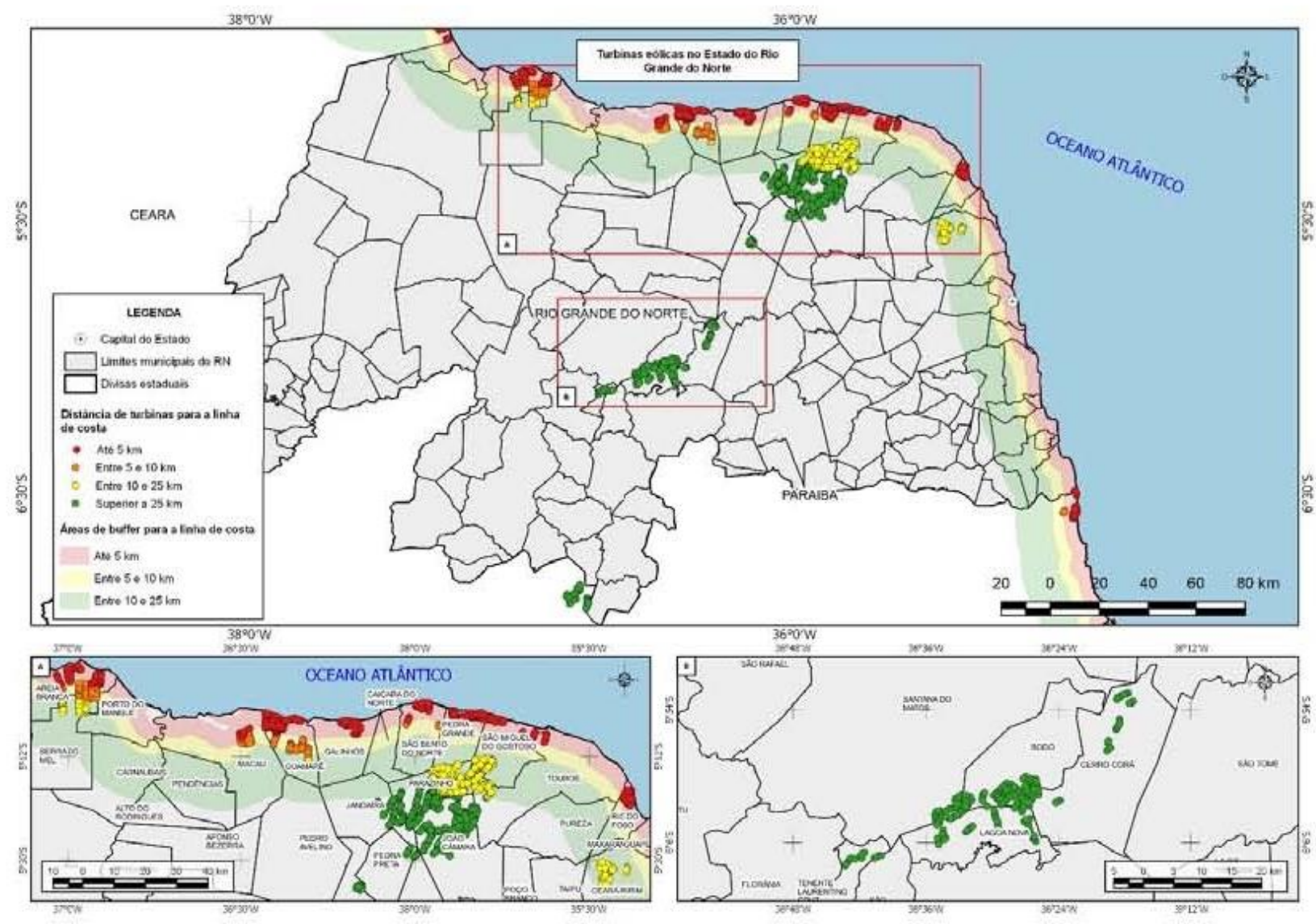

Figura 1 Localização geográfica dos aerogeradores no estado do Rio Grande do Norte. 

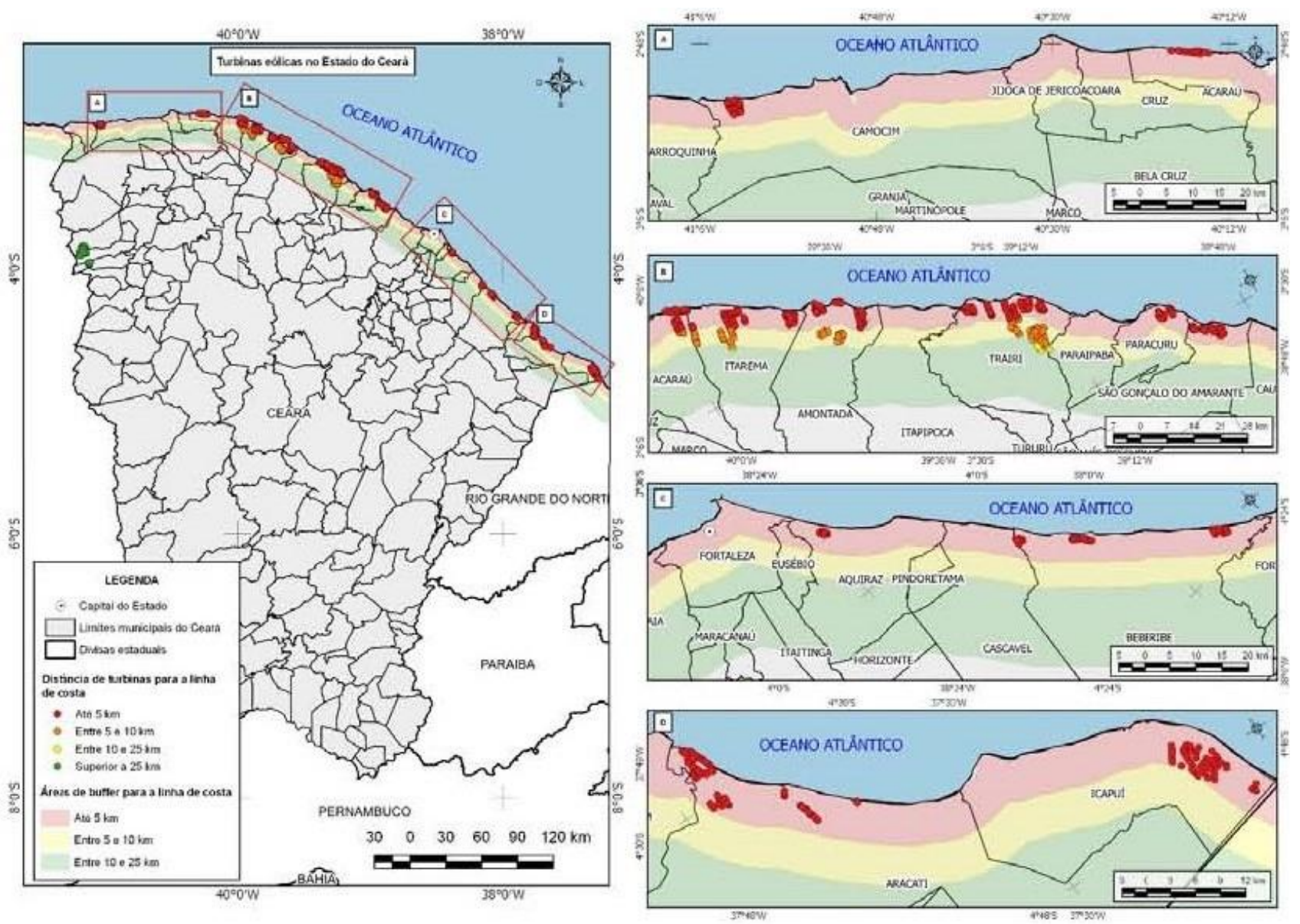

Figura 2. Localização geográfica dos aerogeradores no estado do Ceará.

\section{b. Criação de mapas de "Potencial Eólico"}

O litoral brasileiro se converteu no espaço para investimentos em energia eólica a partir de dados oficiais demonstrando o grande potencial do recurso eólico. No final da década de 1970 foi construído o primeiro documento técnico oficial, em nível nacional, com a finalidade de estimar os dados relativos ao levantamento do potencial eólico no território nacional. O Atlas do Levantamento Preliminar do Potencial Eólico Nacional incluiu o processamento de dados de 389 estações anemométricas de $10 \mathrm{~m}$ de altura, espalhadas em todas as regiões do país. Porém, a altura inadequada das torres e a ineficiência (qualitativa e quantitativa) da coleta de dados existentes, praticamente anulou este documento para o uso em projetos de geração de energia eólica.

Foi somente na década de 1990 que se iniciaram as primeiras medições anemométricas específicas para estudos de viabilidade, com uso de torres de $30-50 \mathrm{~m}$, equipamentos de precisão e procedimentos requeridos para a finalidade de geração de energia. Essas medições concentraram-se inicialmente nos estados do Pará, Ceará, Paraná, Santa Catarina e Rio Grande do Sul. Todavia, em termos nacionais, foi somente a partir da publicação, em 2001, do Atlas do Potencial Eólico Brasileiro, do Ministério de Minas e Energia, que foi possível criar um quadro positivo para a implantação de projetos de energia eólica no país (AMARANTE; BROWER; ZACK, 2001). Este 
documento é referência até os dias atuais, apesar de revelar-se defasado. Nele foram utilizados como fonte de dados 47 estações anemométricas, sendo distribuídas da seguinte forma: 17 no Paraná, 13 na Bahia, 7 na Região Norte (não é especificado o estado), 6 em Santa Catarina, 2 no Ceará e 2 no Litoral (não é especificado o estado). Utilizando métodos e técnicas que agregam análises estatísticas com processamento de imagens de satélite (SPOT) com resolução espacial que varia de 3,6 a $15 \mathrm{~km}$, este documento mostra um potencial nacional aproveitável com velocidade dos ventos de 3,5 a $9 \mathrm{~m} / \mathrm{s}$ para $50 \mathrm{~m}$, extrapolando os dados espacialmente (para todas as regiões do país) e temporalmente (considerando intervalos trimestrais). Os resultados sugerem que as maiores médias anuais de velocidade dos ventos estão nos litorais Norte (Pará e Amapá), Nordeste (Rio Grande do Norte, Ceará e Piauí), Sudeste (Rio de Janeiro e Espírito Santo) e Sul (Santa Catarina) e em alguns setores do interior do continente, como no norte de Roraima, no norte da Bahia, no noroeste do Ceará e no leste de Minas Gerais. Em termos sazonais, o período em que a velocidade do vento está mais propícia para a geração de energia são os meses de junho a novembro em quase todas as regiões, com exceção do norte de Roraima em que os ventos têm velocidade mais elevada no período de dezembro a fevereiro.

Todavia, ressalta-se que esse documento, de apenas 44 páginas, é extremamente generalista e não define de forma clara e precisa a metodologia empregada para a obtenção dos resultados expostos. Por exemplo, não são informadas as resoluções espectrais (sensores utilizados) das imagens de satélite, assim como as datas de aquisição das cenas. Outro grave problema diz respeito à quantidade, muito exígua, das torres anemométricas e a omissão de sua localização geográfica, informação fundamental para a obtenção de uma boa análise. Portanto, sabe-se que, na prática, os investidores e empresários do ramo de energia eólica preferem realizar os próprios estudos anemométricos, de forma autônoma, antes de definirem a localização de um projeto de parque eólico.

Os documentos técnicos oficiais não consideraram os diversos fatores sociais, legais, ambientais e de infraestrutura que norteiam as discussões impostas durante a instalação de um parque eólico. Nesse contexto, é importante avaliar os aspectos ambientais da área, considerando-se que as regiões de melhor situação para instalação dos parques se encontram, em geral, nos litorais dos estados ou em áreas montanhosas continentais, ou seja, em paisagens que possuem dinâmicas ambientais frágeis (áreas alagáveis com dunas móveis, manguezais etc.) ou ecossistemas de exceção com presença de fauna e flora da Mata Atlântica (no caso das regiões Sudeste e em setores do Nordeste), e do complexo ecossistema amazônico, no caso das áreas situadas na Região Norte. É também relevante frisar a ausência dos aspectos legais de uso e ocupação dessas áreas, a partir das análises dos zoneamentos ecológico-econômico dos estados, dos planos diretores municipais e planos de manejo das unidades de conservação envolvidos. Em termos sociais, são imprescindíveis relevantes as análises com cunho territorial, no sentido de viabilizar áreas de implantação dos parques que não coincidam com territórios tradicionais (com ou sem demarcação oficial), como terras indígenas, áreas remanescentes de quilombolas, vilas de pescadores artesanais, ribeirinhos e agricultores familiares. Como observamos a seguir, o mapeamento sem contexto político, social e ambiental, como é relatado em outros casos de energia renovável (BAKA, 2016; MCCARTHY; THATCHER, no prelo), pode explicar parcialmente o "social gap" nos casos onde as comunidades se opuseram aos empreendimentos eólicos. 


\section{c. O "social gap" no litoral brasileiro}

Os resultados referentes ao "social gap" são expostos como relatos de estudos de caso em formato de tópicos, com base em trabalhos de campo que ocorreram no período de 2016 a 2018 em quatro localidades atingidas por projetos de energia eólica, descritos a seguir em detalhes: a) Reserva de Desenvolvimento Sustentável Estadual Ponta do Tubarão, Macau/Guamaré, Rio Grande do Norte; b) Galinhos, Rio Grande do Norte; c) Camocim, Ceará; d) Comunidade Cumbe, Ceará.

Reserva de Desenvolvimento Sustentável Estadual Ponta do Tubarão, Macau/ Guamaré, Rio Grande do Norte. O caso de três parques eólicos (183,5 MW e 111 aerogeradores, entrando em operação entre 2011 e 2014) na Reserva de Desenvolvimento Sustentável Estadual Ponta do Tubarão (RDSEPT), situada no litoral setentrional do estado do Rio Grande do Norte (RN), abrangendo parte dos municípios de Macau e Guamaré e do Mar Territorial, mostra como o "social gap" pode ser produzido, criando impactos colaterais negativos na gestão ambiental. A RDSEPT foi criada em 2003 a partir da mobilização das comunidades litorâneas de Barreiras e Diogo Lopes em defesa do território pesqueiro que passou por tentativas de invasão por um grupo estrangeiro interessado em construir um resort e por empreendimentos de carcinicultura entre os anos de 1995 e 2000. A categoria Reserva de Desenvolvimento Sustentável (RDS) constitui um tipo de unidade de conservação de uso sustentável com dois objetivos: a conservação ambiental e a manutenção dos modos de vida das populações tradicionais. As atividades privadas dentro de uma RDS, se estiverem em desacordo com os objetivos básicos da unidade, devem ser paralisadas e desapropriadas.

Com uma área de 12.940 hectares envolvendo ambientes de praia, manguezal, dunas, lagoas e tabuleiro costeiro e uma população total de, aproximadamente, 10.000 habitantes, a RDSEPT, apesar de ainda não ter plano de manejo e zoneamento instituídos, possui um ConseIho Gestor (CG) deliberativo atuante. No ano de 2018, o CG já passou das 160 reuniões realizadas desde a sua criação em 2003. Contudo, a chegada de empreendimentos eólicos com interesse em se instalar dentro da RDSEPT inaugurou um período polêmico e com muitos acirramentos no âmbito do CG.

A primeira vez que o interesse das empresas pelo recurso eólico dentro da RDSEPT apareceu em Ata do CG foi em 20/06/2008 durante a 57ª Reunião Ordinária. Nesse momento foi relatado o interesse de empresa de energia eólica em se instalar na região, mas o órgão gestor (Instituto de Desenvolvimento Sustentável e Meio Ambiente do Estado do Rio Grande do Norte - IDEMA) informou que tudo seria apreciado pelo CG. A pesquisa documental realizada em 58 atas entre os anos de 2006 e 2012 revelou que a entrada de três parques eólicos na RDSEPT não foi um processo pacífico, tampouco foi aprovado por maioria dos membros do CG, pois nunca houve uma votação sobre o assunto. A compreensão do processo de instalação dos parques eólicos na RDSEPT possibilita os seguintes entendimentos:

I) O conselho gestor da RDSEPT não se mostrou, a princípio, contra a ideia da instalação de usinas eólicas;

II) A celeridade imposta pelo IDEMA para a aprovação dos empreendimentos eólicos incomodou os conselheiros que não foram providos de todas as informações necessárias para entender como, quando e onde as usinas seriam instaladas; 
III) Enquanto eram discutidas as questões sobre as eólicas no CG, os empreendimentos já avançavam as etapas do licenciamento ambiental e, inclusive, já iniciavam sua instalação com a limpeza de terreno e alocação de máquinas;

IV) Dada a gravidade da situação, foi formada uma comissão no CG que elaborou um laudo sobre os impactos dos parques eólicos na RDSEPT, apontando diversas situações que promoviam impactos negativos à fauna, as dunas, lagoas e águas subterrâneas, bem como, impactos negativos aos modos de vida tradicionais com a interdição de áreas de passagem de pescadores;

V) A chegada das eólicas promoveu conflitos internos entre as comunidades, especialmente entre aqueles moradores que seriam beneficiados economicamente por meio do recebimento de recursos mensais e aqueles que se mostravam preocupados com os impactos ambientais destes projetos;

VI) Os três parques que se instalaram na RDSEPT não respeitaram a fragilidade dos ambientes naturais, pois as alternativas locacionais não foram discutidas. Com isso, existe hoje um parque instalado na restinga a 30 metros de distância do mar, outro parque está instalado sobre um campo de dunas móveis e o último está instalado no tabuleiro costeiro (Figura 3).

Este caso revela o quanto o governo estadual e o IDEMA estavam comprometidos com a política de expansão da energia eólica no Rio Grande do Norte e se mostravam distantes dos interesses das populações locais tradicionais, que tinham como princípio a preservação ambiental dos sistemas naturais potiguares, o que, na realidade, era para ser a principal missão do IDEMA. Mesmo diante dos fortes embates no CG e a ausência de posição definitiva sobre a viabilidade destes empreendimentos, o IDEMA e os investidores optaram por avançar com a instalação dos parques. Observa-se que, mesmo sendo uma unidade de conservação com um conselho ativo e deliberativo, a RDSEPT enfrentou um processo de entrada de empreendimentos eólicos brusco, sem planejamento locacional e sem a efetiva deliberação dos conselheiros. Nesse sentido, o processo de discussão para a implantação e operação de usinas eólicas na RDSEPT abalou a confiança dos conselheiros no órgão gestor, levando a um desgaste que vem prejudicando a governança da Reserva. Acrescenta-se que a inexistência de instrumentos básicos de gestão como Plano de Manejo e Zoneamento contribuíram para facilitar o processo de instalação e operação das usinas eólicas na RDSEPT.

Galinhos, Rio Grande do Norte. Outro caso potiguar que destacamos é o de dois parques eólicos (119 MW a partir de 71 aerogeradores), inaugurados em 2012, no município de Galinhos (2.715 habitantes), a $160 \mathrm{~km}$ de distância de Natal. Todavia, o projeto inicial previa a instalação de três parques eólicos que não se concretizou por completo devido aos fortes protestos locais contra a instalação dos empreendimentos sobre o campo de dunas móveis. Inicialmente, a população local, tendo como principais motivadores a associação dos bugueiros, e como parceiros os donos locais de hotéis e restaurantes e a associação dos barqueiros, uniu-se em prol da conservação do campo de dunas. O complexo de dunas móveis interliga o continente à flecha litorânea onde a infraestrutura municipal e as residências estão instaladas, e faz parte de um dos mais importantes cartões-postais da região, o que estimula o fluxo de turistas para o município, que tem como fonte econômica básica os serviços que são ofertados aos visitantes (transporte, hospedagem, alimentação e lazer). 


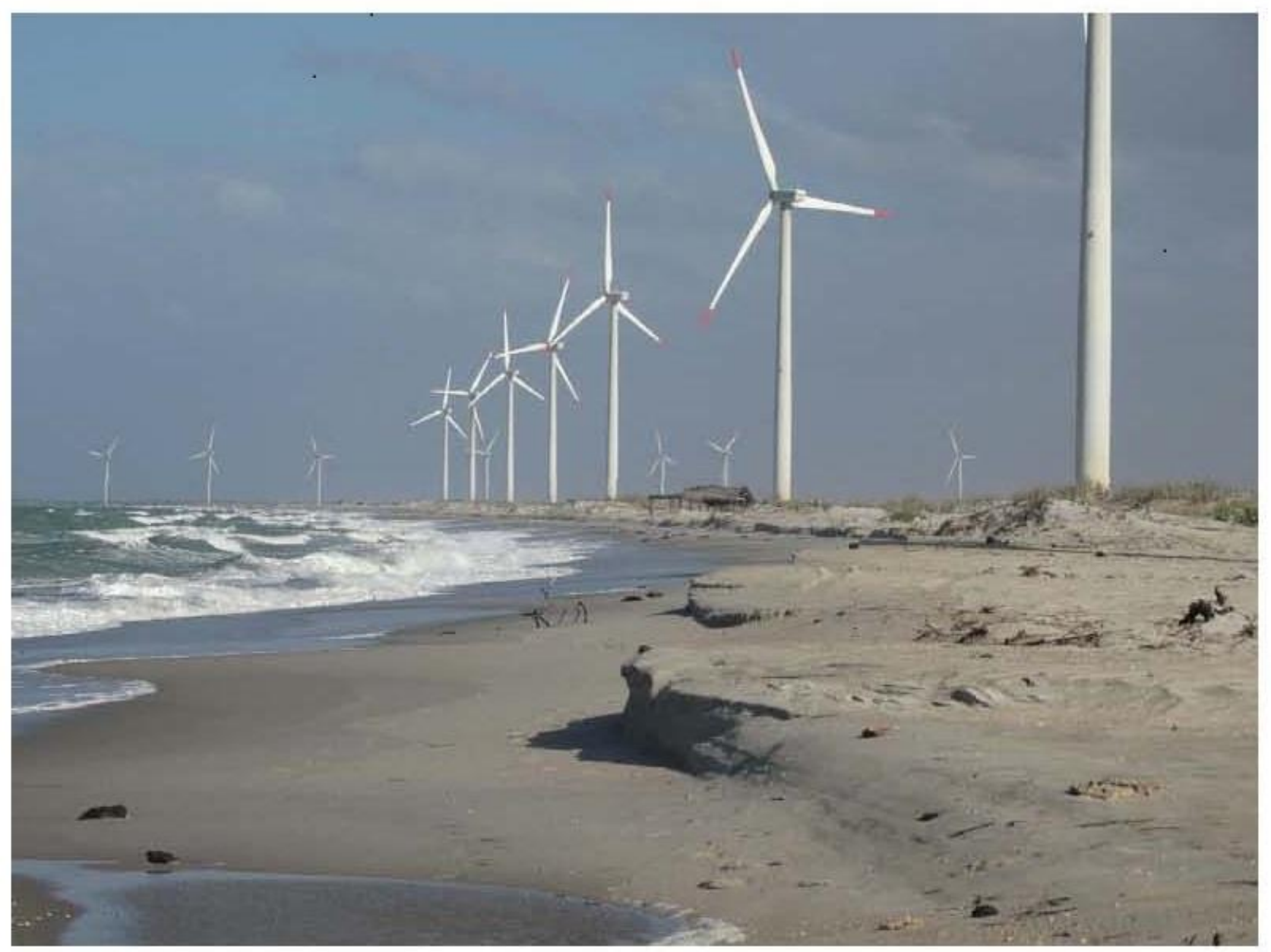

Figura 3. Aerogerador dentro da Reserva de Desenvolvimento Sustentável Estadual Ponta do Tubarão (GUIMARÃES, Mai/2017).

Os protestos tiveram como fonte de inspiração as postagens online de atos realizados na praia de Flecheiras, no município de Trairi, Ceará, que ficou conhecido como "SOS Dunas", devido um abraço coletivo que foi feito às dunas locais onde existia um projeto de implantação de parque eólico, que ocorreu poucos meses antes do anúncio da implantação do parque em Galinhos. Todavia, apesar dos manifestantes de Galinhos terem tido relativo sucesso com os protestos contra a instalação do parque, por meio de caminhadas coletivas, abraços às dunas e exposição de faixas, militâncias online e criação de blogs, em Flecheiras o parque foi construído em sua totalidade e a comunidade ficou sem acesso à área implantada e com impacto visual desagradável e permanente.

Além da comunidade de Galinhos ter conseguido a anulação da construção do terceiro parque e a realocação do segundo parque, as associações de bugueiros e de barqueiros negociaram o trânsito de turistas dentro do parque, uma vez que a paisagem natural integrada aos aerogeradores demanda, muitas vezes, curiosidade por parte dos turistas e, em alguns casos, é usado como atração turística pelos próprios prestadores de serviço locais (Figura 4). Porém, ainda assim existe uma tensão entre o turismo e o empreendimento eólico. Segundo Farias (2017), em pes- 
quisa etnográfica, o fato do turismo ser praticamente todo gerido somente por habitantes locais, cria uma dicotomia entre a atividade turística, vinculada ao lugar e aos saberes locais, e o parque eólico que representa uma distorção da vida do lugar e revela-se como um símbolo exógeno do capital externo e desagregador, alienando o lugar e retirando toda a afetividade com o território.

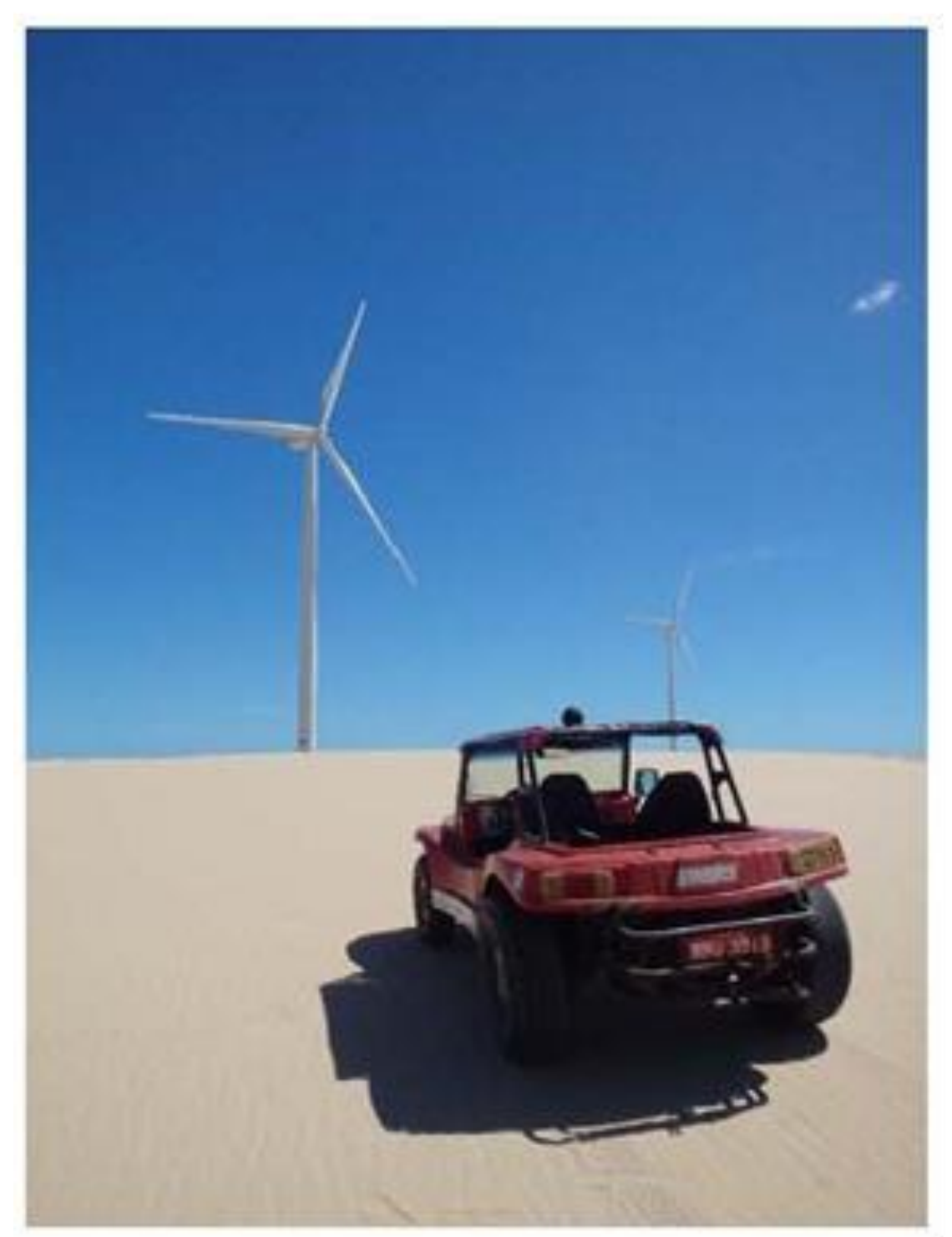

Figura 4. Buggy dentro do parque eólico em Galinhos, RN (BRANNSTROM, mai/2016).

Amarelas, Camocim, Ceará. Amarelas é distrito de Camocim e abriga uma das comunidades mais impactadas negativamente pela implantação de um parque eólico no Brasil, a comunidade de Xavier. Xavier dista cerca de $350 \mathrm{~km}$ a oeste de Fortaleza e ainda nos tempos atuais, apresenta sérios problemas ocasionados pela implantação e operação do parque eólico que foi inaugurado em seu território em 2009 (104,4 MW e 50 aerogeradores) (Figura 5). 


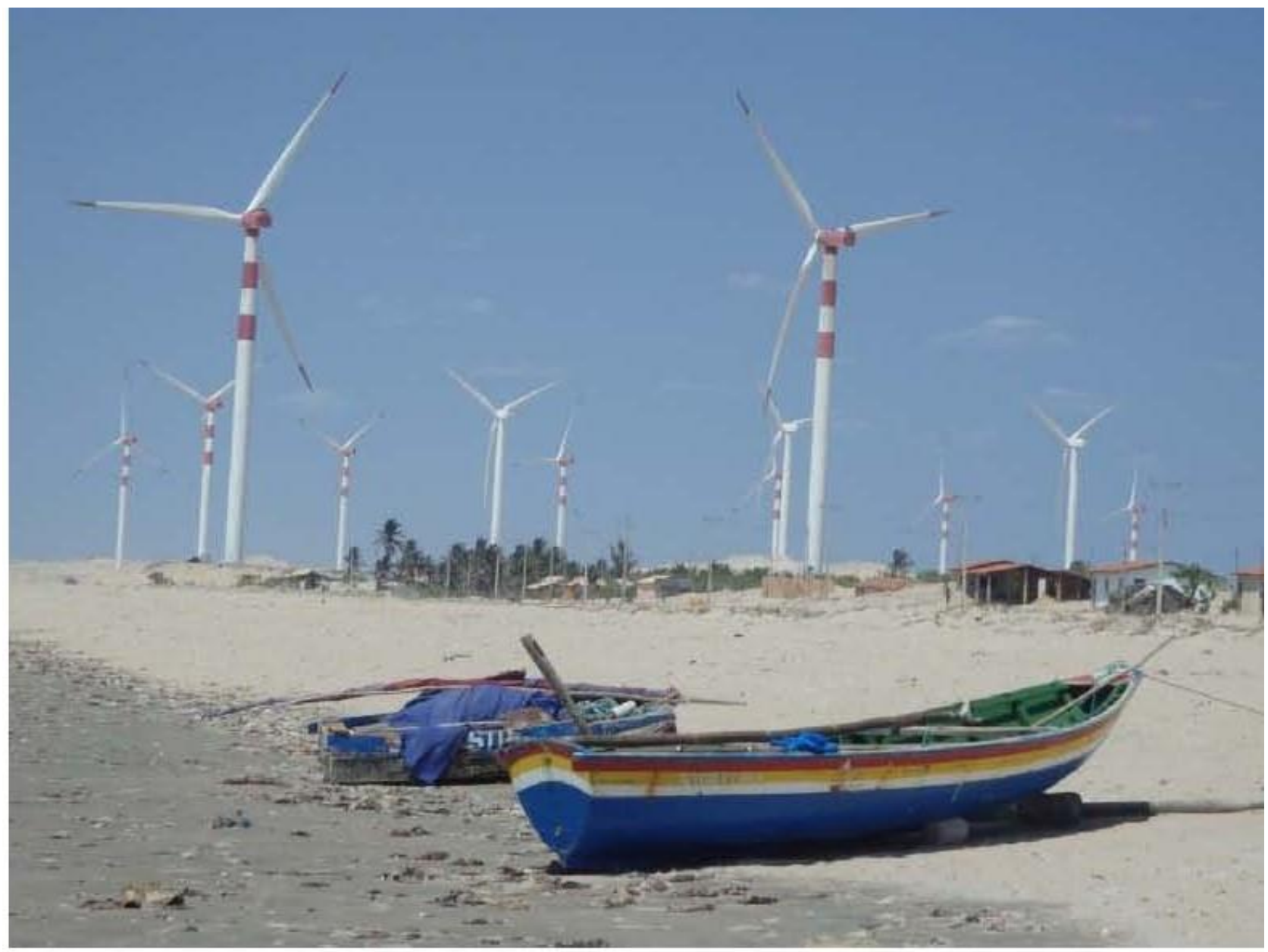

Figura 5. Parque eólico e a comunidade de Xavier (BRANNSTROM, ago/2015).

Desde a etapa de licenciamento do projeto, os moradores de Xavier têm problemas com as empresas que, de forma categórica e com a conivência do Estado, invisibilizaram a comunidade a ponto de negar a sua presença no território, excluindo-a dos mapas e relatórios técnicos no início do processo de planejamento. Gorayeb et al. $(2018,2016)$ e Meireles et al. (2013) relatam que os impactos socioambientais mais graves que os moradores de Xavier sofreram dizem respeito à proibição, por parque do parque eólico, em transitar nos acessos que a comunidade utilizava para a sede do distrito e o centro do município, além do fato de, durante a construção do parque, ter havido uma série de más condutas técnicas (engenharia civil), ocasionando a destruição de lagoas interdunares importantes à pesca e, consequentemente, redução sistemática dos níveis de segurança alimentar dos habitantes locais. As reivindicações da comunidade, em termos judiciais via Defensoria Pública de Camocim e com apoio da Diocese de Tianguá (Igreja Católica), incluíram livre utilização da estrada privatizada pelo parque eólico, e construção de 22 casas de alvenaria e uma sede da associação dos moradores com freezers para armazenar os pescados. A empresa, atendendo parte das reivindicações, liberou para a associação, em 2013, o valor de R $\$$ 540.000 como política de compensação pelos danos ambientais. Em visita de campo realizada em fevereiro de 2018, tivemos relatos de que a comunidade está atualmente reivindicando diretamen- 
te à empresa, sem o apoio da igreja e da defensoria, a doação mensal de cestas básicas, devido ao aumento, ano a ano, da insegurança alimentar das famílias. Até o momento as requisições não obtiveram êxito.

Essa situação pode ser relevada em nossa pesquisa, quando em 2017 aplicamos aleatoriamente 78 questionários nas três comunidades próximas ao empreendimento eólico instalado na Praia de Xavier (Xavier, Ziú e sede de Amarelas, com população total estimada em 369 habitantes). Foram constatadas a baixa representatividade dos habitantes nas audiências públicas realizadas antes da implantação do projeto, assim como o alto grau de insatisfação dos moradores com a falta de oportunidades para esclarecer e expressar dúvidas antes do projeto ser implantado (Tabela 3). A presença das comunidades em audiências públicas do licenciamento ambiental foi negada por $100 \%$ da comunidade de Ziú e mais de $80 \%$ em Amarelas (sede) e Xavier. De modo similar, a falta de oportunidades para expressar preocupações e esclarecer dúvidas antes do projeto ser aprovado foi contestada por $79,5 \%$ da população, indicando uma comunicação insuficiente entre desenvolvedores do projeto (órgãos públicos e empresários) e as comunidades locais, verticalização na condução do projeto e dificuldade de interferência e acesso às informações pelas comunidades.

Tabela 3. Percepção sobre a consulta pública em Camocim, CE

\begin{tabular}{|c|c|c|c|c|c|c|c|c|}
\hline Afirmação & \multicolumn{5}{|c|}{ Nível de concordância ${ }^{a}$} & & & \\
\hline $\begin{array}{l}\text { Participei da audiência pública } \\
\text { para aprovação do parque } \\
\text { eólico }\end{array}$ & $1^{b}$ & 2 & 3 & 4 & 5 & Média & Mediana & D.P.c \\
\hline Amarelas & 3,5 & 0,0 & 7,0 & 3,5 & 86,0 & 4,7 & 5,0 & 0,9 \\
\hline Xavier & 7,7 & 0,0 & 7,7 & 0,0 & 84,6 & 4,5 & 5,0 & 1,2 \\
\hline Ziu & 0,0 & 0,0 & 0,0 & 0,0 & 100,0 & 5,0 & 5,0 & 0,0 \\
\hline Total $(n=78)$ & 3,8 & 0,0 & 6,4 & 2,6 & 87,2 & 4,7 & 5,0 & 0,9 \\
\hline $\begin{array}{l}\text { Tive grande oportunidade de } \\
\text { expressar minhas preocupa- } \\
\text { ções e esclarecer dúvidas } \\
\text { antes do projeto ser aprovado }\end{array}$ & 1 & 2 & 3 & 4 & 5 & Média & Mediana & D.P. ${ }^{c}$ \\
\hline Amarelas & 3,5 & 3,5 & 12,3 & 12,3 & 68,4 & 4,4 & 5,0 & 1,1 \\
\hline Xavier & 0,0 & 7,7 & 15,4 & 0,0 & 76,9 & 4,5 & 5,0 & 1,1 \\
\hline Ziu & 0,0 & 0,0 & 25,0 & 12,5 & 62,5 & 4,4 & 5,0 & 0,9 \\
\hline Total $(n=78)$ & 2,6 & 3,8 & 14,1 & 10,3 & 69,2 & 4,4 & 5,0 & 1,0 \\
\hline
\end{tabular}

a 1- Concordo totalmente; 2- Concordo em parte; 3- Nem concordo, nem discordo; 4- Discordo em parte

5: Discordo totalmente.

${ }^{b}$ Valores percentuais para apoio e oposição

c Desvio Padrão

Fonte: questionário aplicado em campo.

Destaca-se que a desvalorização da percepção comunitária foi um dos fatores que resultou em uma avaliação deficiente dos impactos socioambientais negativos. A comunidade de Xavier, por exemplo, foi responsável por reivindicações durante a construção do parque eólico em virtude do aterramento de lagoas interdunares importantes à pesca, que compõe a base alimentar e econômica da comunidade, e foi contra a privatização de espaços comuns utilizados para o desloca- 
mento/acesso a outras comunidades.

A desconsideração da organização, da tradição local também é percebida em relatos de moradores, indicando que uma mudança arbitrária no nome da praia de Xavier, realizada pela empresa desenvolvedora do parque eólico, surpreendeu a comunidade, pois "Todo mundo conhecia como Praia de Xavier aí depois eles botaram o nome de Praia Formosa [...]".

Assim, foi possível verificar que a baixa participação da população local durante o processo decisório do parque eólico deveu-se à pouca interação entre as partes interessadas durante o planejamento. Para Fast et al. (2016), como as reuniões públicas tendem a se tornar espaços de protestos e oposição, então, tornam-se indesejadas por desenvolvedores do projeto que priorizam alcançar taxas satisfatórias de energia elétrica por meio da fonte eólica. A falta de comunicação durante o planejamento do parque eólico em Camocim também conduziu a níveis de confiança baixos enquanto a capacidade de afetar os resultados do projeto. A justiça participativa não existiu neste caso.

Comunidade do Cumbe, Aracati, Ceará. O segundo caso cearense que destacamos é o da comunidade do Cumbe, localizada no município de Aracati que dista $150 \mathrm{~km}$ a leste de Fortaleza e, em 2008 recebeu a instalação de um parque eólico em seu território (57 MW e 28 aerogeradores). A comunidade do Cumbe, com 702 habitantes, já possuía conflitos internos antes da instalação do parque eólico, devido à construção de tanques de carcinicultura em 1998 (QUEIROZ et al., 2013), tendo como consequência o desmatamento do mangue e a privatização dos canais fluviais que a comunidade outrora utilizava livremente para atividades de pesca e lazer. Essa situação segmentou opiniões internas entre os moradores, considerando-se que algumas famílias se beneficiaram da carcinicultura, como proprietários ou trabalhadores nas fazendas de terceiros, e as famílias que se opuseram à entrada dos empreendimentos foram expropriadas dos espaços comunitários e não obtiveram nenhuma benfeitoria ou vantagem da atividade. Em meio a essa atmosfera desagregadora e conflituosa, em 2008 iniciaram-se as construções do parque eólico que se instalou no campo de dunas que integra o território do Cumbe e que dá acesso à zona de pesca marítima, assim como provê lagoas onde se realizava pesca continental durante o período chuvoso.

A construção do parque eólico modificou as relações comunitárias, alterou a forma como os residentes usufruíam dos recursos naturais e espaços de lazer (Chaves et al., 2017) e influenciou no surgimento de diversos movimentos de rejeição ao empreendimento, desencadeando na participação dos residentes em ações legítimas, periódicas e não violentas. No Cumbe, o ativismo público tem-se manifestado através de ações coletivas como I) passeatas na sede da Prefeitura Municipal; II) reuniões com moradores e representantes do empreendimento eólico; III) fechamento da estrada principal que permite acesso ao parque; IV) campanhas de mobilização nas redes sociais e V) moções de ações civis públicas contra o empreendimento eólico. Brown (2011) registrou uma das principais manifestações da localidade em setembro de 2009, quando lideranças da comunidade bloquearam a estrada principal que permite acesso ao empreendimento eólico por 19 dias.

Em 2018, constatamos que ainda existem conflitos entre residentes e o empreendimento eólico, em especial pelo posicionamento da empresa eólica que em 2017 solicitou a reintegração de posse de uma área de faixa de praia utilizada pelos residentes para apoio à pesca no mar (Figura 6) e pela construção de um museu comunitário oriundo de um Termo de Ajustamento de Conduta 
pelos danos ocasionados aos sítios arqueológicos no início da construção do parque. A comunidade é gerida por duas associações e a empresa eólica direcionou a gestão do museu para a Associação de Moradores do Cumbe e Canavieira que é contrária as ações da Associação Quilombola do Cumbe, esta última responsável por iniciar o processo de mitigação dos danos causados aos sítios arqueológicos e por mover ações contra o parque. A disputa pela gestão do museu tem acirrado os conflitos entre os grupos familiares e contribuído para que parte da comunidade mantenha sua oposição ao projeto eólico e outra parte mantenha-se a favor do empreendimento. Brown (2011) evidenciou que o Cumbe está imerso em diversos impactos negativos com escassos benefícios diretos, adquiridos após inúmeros protestos. Os principais conflitos ainda se referem ao uso pleno do território e aos impactos que o parque eólico ocasionou aos seus meios de vida e espaços de lazer.

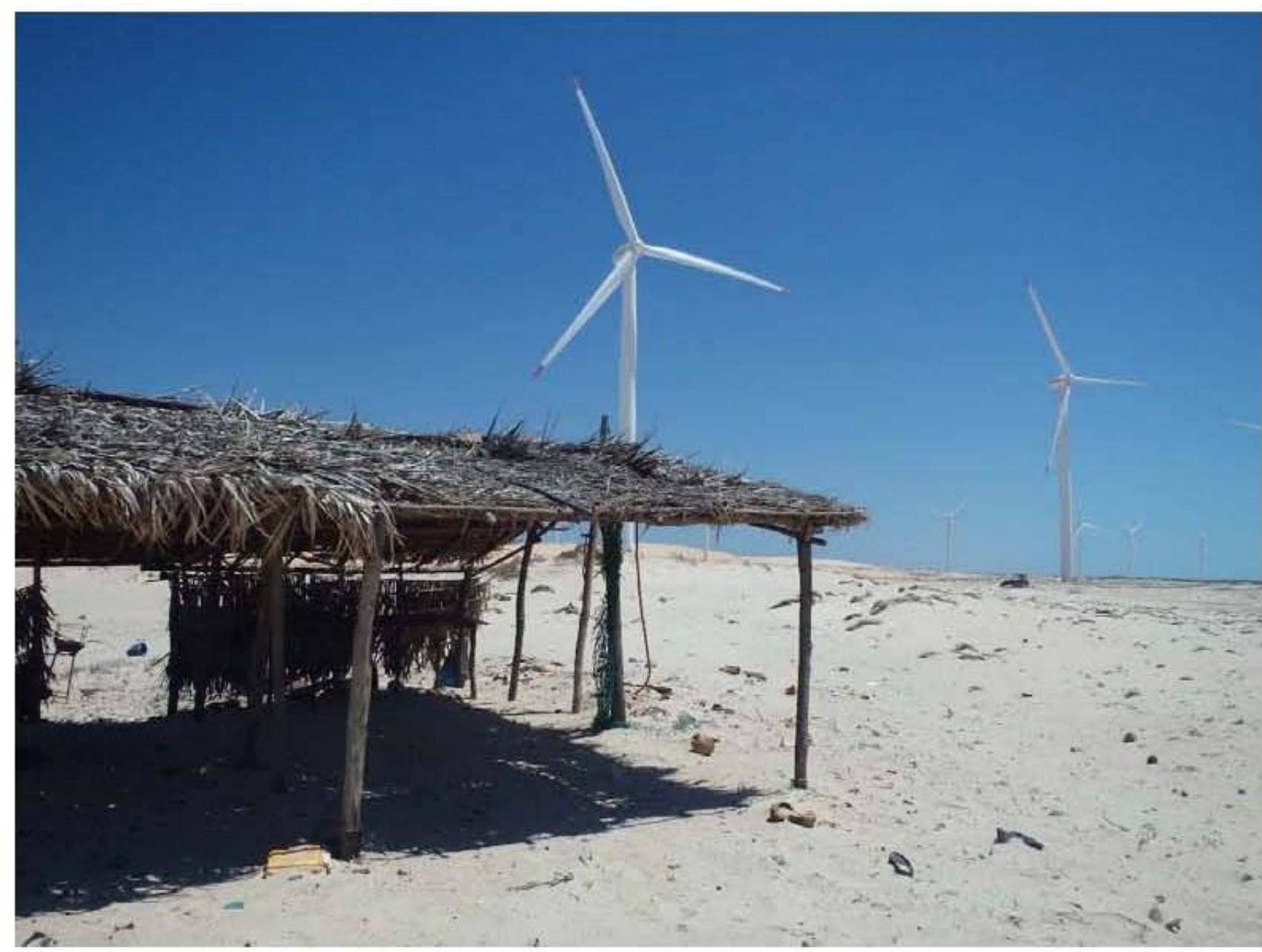

Figura 6. Aerogeradores próximos à barraca de apoio de pesca da comunidade Cumbe (BRANNSTROM, ago/2017).

\section{d. Na contramão do "social gap": aceitação social dos parques eólicos}

Os resultados referentes à aceitação social são expostos como relatos de estudos de caso em duas localidades atingidas por projetos de energia eólica, descritos a seguir em detalhes: a) Itarema, Ceará; b) Osório, Rio Grande do Sul. 
Assentamento Fazenda Patos, Itarema, CE. O caso do assentamento Fazenda Patos, localizado no município de Itarema, litoral oeste do estado do Ceará, a cerca de $198 \mathrm{~km}$ de Fortaleza, mostra os fatores que podem criar condições de aceitação e apoio aos empreendimentos eólicos (Figura 7). O assentamento foi criado em 1998 sob gerenciamento do Instituto de Desenvolvimento Agrário do Ceará (IDACE), com 341 hectares e 18 famílias assentadas que exploram a agricultura da mandioca, coco, milho, feijão e banana, com parte de suas plantações irrigadas, além de ter criação de ovinos e bovinos. O distrito de Patos teve, em 2017, a implantação de dois parques eólicos (48,3 MW e 23 aerogeradores), sendo que foram instaladas 9 torres dentro das terras pertencentes ao assentamento. A pesquisa de campo indica que o caso apresenta uma exceção entre as comunidades do litoral oeste do Ceará, uma vez que os parques eólicos têm boa aceitação dos habitantes do assentamento e a empresa possui políticas, projetos e programas que beneficiam os moradores de forma direta e indireta.

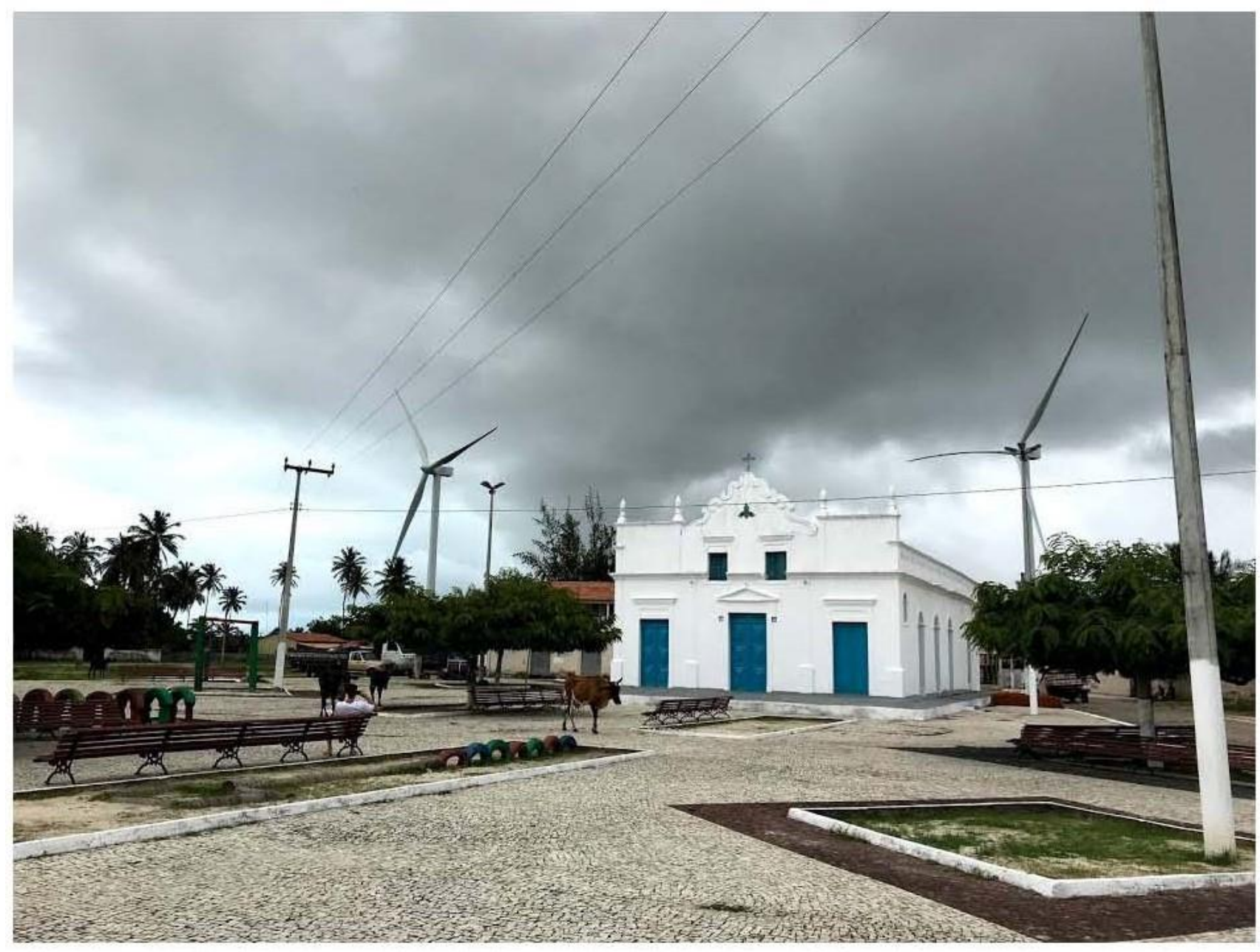

Figura 7. Aerogeradores do parque eólico em Patos (SOUZA, fev. 2018).

Em 2018, observamos que todas as famílias assentadas recebem benefício financeiro referente à produção mensal energética dos aerogeradores, via associação de moradores, por meio do repasse de $1,5 \%$ sobre a produção bruta mensal de cada aerogerador, considerando-se rea- 
justes periódicos de índices econômico-financeiros governamentais. Adicionalmente, os associados são favorecidos com projetos de desenvolvimento local financiados pela empresa, como o Projeto de Estruturação das Cadeias Produtivas do Coco e da Mandioca, que promoveu oficinas em 2017 que abordavam técnicas sustentáveis de produção consorciada de coco e mandioca, técnicas de gestão de empreendimentos e técnicas de comercialização. Além disso, a empresa que administra os parques subsidiou uma obra de uma ponte que interliga algumas comunidades e financiou parte de um sistema de irrigação de coqueiros de uma plantação coletiva. Todavia, o maior benefício que a empresa eólica proporcionou aos moradores em menos de um ano de atividade, foi a quitação da dívida no valor de $\mathrm{R} \$ 157.000,00$ que os assentados tinham junto ao banco estadual (a associação poupou os primeiros rendimentos da produção da energia e negociou um abatimento junto ao banco e pagou à vista o valor devido), por meio do Programa Cédula da Terra do Banco do Nordeste (BNB), aumentando o nível de aceitação de todos os moradores.

Osório, Rio Grande do Sul. O parque eólico com 150 aerogeradores e 300 MW de potência instalada do município de Osório (44.468 habitantes) foi inaugurado em dezembro de 2006 e está localizado no litoral do Rio Grande do Sul, a cerca de 100 km de distância de Porto Alegre. O parque foi instalado em terrenos de 11 proprietários rurais, em fazendas de criação de gado, que recebem valores relativos aos aluguéis e pagamentos de royalties que variam conforme a produção mensal de cada torre (BIER, 2016). A população que vive no entorno do parque e que, de alguma forma, sofre algum tipo de impacto direto ou indireto das construções, foi entrevistada no trabalho de Bier (2016) e, como resultado, a autora demonstra que todos os questionários aplicados durante a pesquisa, com moradores, empresários, turistas etc, denotam aspectos positivos da instalação do parque, inclusive em termos paisagísticos. Os entrevistados acreditam que os visitantes são atraídos pela paisagem que integra o ambiente natural de pasto e alagado com os aerogeradores que têm viés, ao mesmo tempo, tecnológico e sustentável.

O Centro Contemplativo de Visitas do Parque, um centro de visitantes, é o primeiro neste modelo do Brasil, inaugurado em novembro de 2016 (Figura 8). A estrutura é composta por estacionamento, mirante, tendas externas, painéis e vídeos informativos e um funcionário do parque recepciona os visitantes. A estrutura é utilizada cotidianamente pela população do município e de regiões próximas, por meio de visitação sistemática dos alunos das escolas de Ensino Básico e Técnico, além de faculdades locais, e possui um calendário de eventos anuais, como a Corrida do Vento, organizada em parceria com a Prefeitura Municipal e que, em 2016, teve 400 participantes. O centro de recepção funciona por meio de cadastro de visitas via Internet e possui infraestrutura interessante com sinalização vertical e horizontal, placas informativas com detalhamentos sobre os equipamentos, potência do parque, estrutura, tecnologia utilizada nas torres, transformando-se em uma experiência informativa diferenciada. 


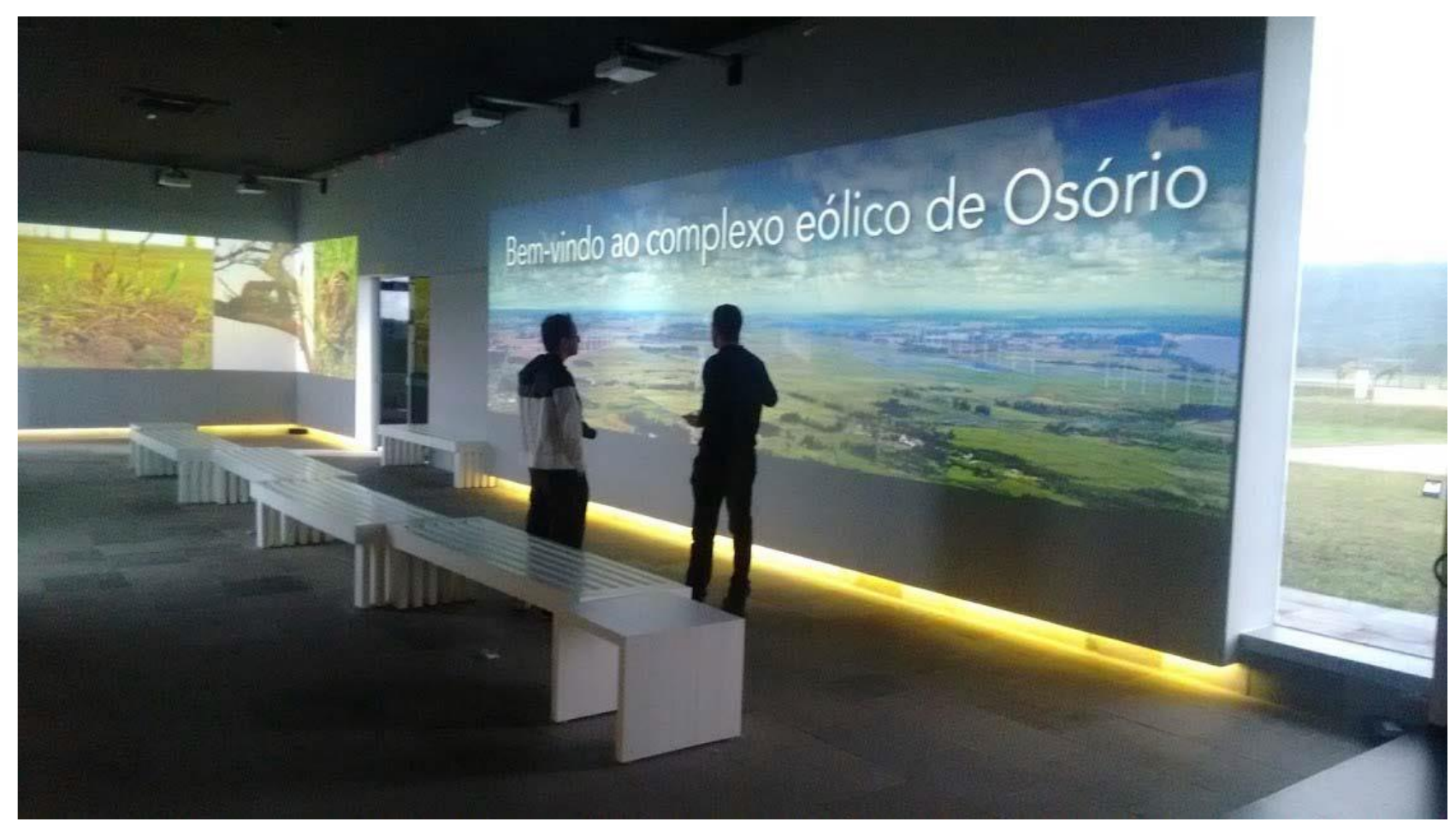

Figura 8. Centro de visita do Complexo Eólico Osório (GORAYEB, out. 2017).

\section{Discussão}

O que se percebe atualmente, especialmente no Nordeste brasileiro, é que grande parte dos conflitos existentes entre empresa e comunidade local têm seus problemas enraizados no fato do empreendimento não ter considerado, devidamente, os aspectos fundiários, políticos e sociais envolvidos, reproduzindo o "social gap". Dentro da diversidade de fatores, destacamos a questão fundiária e a justiça participativa.

No caso dos parques eólicos se localizarem perto de comunidades "invisibilizadas", reparamos que os seus territórios se tornaram cobiçados (LEROY; MEIRELES, 2013) pelos investidores. Este tipo de caso tem relação direta com o "green grabbing" (FAIRHEAD et al., 2012), já que representa os casos em que as elites locais colaboraram com consultores ambientais para produzir os relatórios necessários para o licenciamento, mantendo as comunidades "invisíveis" e usando seu acesso privilegiado às instituições econômicas para obter royalties e arrendamentos, negando as instituições econômicas que beneficiariam as comunidades afetadas (GORAYEB et al., 2018). A insegurança da posse da terra, que podem ser invisíveis para o empreendimento eólico, é um problema de primeira ordem, explicando o surgimento de conflitos no litoral brasileiro. Em Camocim, a invisibilidade e a falta de segurança fundiária da comunidade Xavier criaram as condições para que a comunidade não fosse consultada e só recebesse benefícios depois de reivindicações. Na RDS Ponta do Tubarão, o território da RDS e a sua governança foram invisibilizados pelo próprio Estado em função do licenciamento do empreendimento. Na comunidade do Cumbe, houve um processo parecido de invisibilização da comunidade, uma vez que foi desconsiderado que os campos de dunas faziam parte do território tradicional comunitário. 
Reparamos a questão fundiária como um fator diferencial nos casos de Patos (Itarema) e em Osório, onde os empreendimentos eólicos se localizaram dentro de um território com propriedades já bem estabelecidas. Nestes casos, as empresas agiram de forma diferenciada com os proprietários, assentados ou fazendeiros de gado, e usaram instrumentos econômicos já bem estabelecidos, como contratos de arrendamento e pagamento de royalties, atendendo assim à justiça distributiva. As pesquisas futuras devem determinar se essas ações diferenciadas das empresas se devem à questão fundiária em que o empreendimento se localiza, ou se deve aos fatores internos da empresa, como políticas de responsabilidade social, e o próprio aprendizado das empresas que aprendem sobre o conflito em uma localidade e, no próximo empreendimento, obedecem outro padrão de interação com a comunidade afetada.

A participação da população afetada, um tema fundamental para a "participação cidadã no planejamento" na justiça participativa (WALKER, BAXTER, 2017), é outra variável a ser aprofundada pela perspectiva da justiça. Segundo Gorayeb e Brannstrom (2016), no Ceará o processo de planejamento é dominado pelas empresas, proprietários de terras, políticos com interesses próprios e técnicos, que tornam as comunidades "invisíveis" em decisões locacionais e não ocorre efetivo acesso a informações e possibilidades de participação e interferência no projeto em audiências públicas. Reparamos, com levantamentos em campo, esta realidade no caso de Camocim, enquanto no caso da RDS Ponta do Tubarão houve uma participação de fachada, já que a decisão para implementar o parque eólico foi feita longe do Conselho Gestor, apesar do Conselho ter esta atribuição por ser deliberativo. Assim, observamos duas versões do processo que Bell et al. (2005) denominaram "definir-anunciar-defender" (decide-announce-defend), no qual a decisão é tomada pelos proponentes do projeto, anunciada e defendida da crítica pública, de forma vertical e centralizada. Assim, considera-se que estratégias para incentivar a participação e o compartilhamento de informações devem ser pensadas, entretanto, irão enfrentar a baixa confiança nas instituições públicas. Pesquisas futuras devem determinar outras possíveis variações no modelo "definir-anunciar-defender" e as suas implicações e impactos nas políticas do país.

Em comparação com as estimativas de Harvey et al. (2017) e Harvey e Dew (2016), que demonstraram que $64 \%$ dos parques eólicos e $51 \%$ da capacidade instalada na Austrália está localizada dentro da faixa de $25 \mathrm{~km}$ de distância da linha de costa, a energia eólica brasileira, com exceção do estado do Ceará (com 68\% da capacidade instalada), representa menor concentração, com $46 \%$ dos aerogeradores localizados nesta faixa. Ainda assim, os impactos socioambientais sintetizados neste trabalho refletem em um novo olhar sobre os impactos que o litoral brasileiro está exposto.

Bell et al. (2013) defenderam a necessidade de uma compreensão mais detalhada da política e do poder em casos particulares de implantação de energia eólica. Os conflitos que emergem no litoral do Nordeste brasileiro indicam que os países em desenvolvimento apresentam um novo repertório de processos, como insegurança na posse da terra, instituições econômicas fracas e judiciário disfuncional, que normalmente não são encontrados nos lugares que receberam a maior atenção de cientistas sociais interessados em aceitação social ou rejeição popular dos grandes empreendimentos de energia renovável. A presença de conflitos territoriais relacionados às comunidades tradicionais, por um lado, e as redes de intermediários obscuros que apoiam os parques eólicos, por outro, apresentam um novo fenômeno que pode estar presente em países em desenvolvimento com alto potencial eólico e investidores ansiosos. A experiência brasileira na energia 
eólica mostra que o entrelace das elites locais com os investidores no sentido de beneficiamento financeiro, aprimoram métodos de corrupção para aquisição de territórios de forma ilícita para essas elites. Os projetos são implantados onde e quando os políticos, administradores, e as elites locais se beneficiam diretamente com o empreendimento eólico. Além de ter bom recurso eólico, como o Atlas Eólico mostra, os locais onde os parques eólicos são implementados frequentemente são locais onde algum político de nível regional ou local deve lucrar ou ter benefícios diretos para que o empreendimento seja implantado. Reparamos este fenômeno explicitamente nas comunidades onde as pessoas tiveram impactos negativos. Isto significa que o problema do "social gap" brasileiro é um problema de corrupção e beneficiamento ilícito que pesquisas futuras devem aprofundar.

\section{Conclusão}

Novos impactos socioambientais sobre o litoral brasileiro são observados, devido ao fato de que aproximadamente $46 \%$ dos aerogeradores brasileiros estão localizados em até $25 \mathrm{~km}$ de distância da linha costeira e $26 \%$ estão situados em até $5 \mathrm{~km}$ de distância da linha de costa. A abordagem do "social gap" permite entender os conflitos envolvendo os empreendimentos eólicos. Os casos sintetizados aqui mostram que o crescimento rápido da energia eólica no litoral brasileiro foi devido, não somente a um "bom recurso eólico", mas especialmente a figuras políticas de nível regional ou local que pudessem lucrar ou obter benefícios diretos com a implantação do empreendimento eólico.

É importante ressaltar as divergências sobre como as empresas recebem ou não o público nos parques eólicos. Grande parte das informações expostas ao público no centro de visitação de Osório é, muitas vezes, arduamente omitida pelos empreendedores da energia eólica nos parques eólicos localizados no Nordeste. Isto revela-se no fato dos autores terem tido dificuldades em obter informações até mesmo nos órgãos estaduais responsáveis pelo licenciamento e, muitas vezes, não puderam tirar fotografias in loco na parte externa do empreendimento, em via pública, devido a constrangimentos por parte dos vigilantes privados dos parques. Essa situação abre margem para conclusões controversas em relação à postura empresarial, às demandas das elites locais e aos órgãos ambientais de licenciamento do Ceará e do Rio Grande do Norte, uma vez que se pode perceber que quanto menor a transparência nos processos de instalação e operação dos parques, desde a etapa de aquisição das terras, maiores serão os níveis de impacto do empreendimento e, por consequência, menor será a probabilidade de aceitação por parte da comunidade. Isso se reflete diretamente na acessibilidade aos ambientes do parque, transformando-se em um prejuízo adicional à comunidade local atingida que, considerando a vocação natural do Nordeste para o Turismo, poderia aproveitar mais esta infraestrutura para obter benefícios de forma socialmente mais justa e compartilhada.

Por fim, sugerimos temáticas para aprofundamento de pesquisas futuras, com base no conceito de justiça participativa e distributiva e que tenham como foco o comportamento variado das empresas eólicas em relação aos níveis de impactos socioambientais dos empreendimentos. Além de sofisticar as análises das circunstâncias políticas dos parques eólicos, repara-se a falta de pesquisas com base de amostragem aleatória usando questionários padronizados, para apro- 
fundar o conhecimento das opiniões sobre a energia eólica nos locais onde os parques foram instalados. A falta de conhecimento do desconforto com os ruídos que os equipamentos fazem e que, conforme relatos de moradores próximos às torres, ocasiona constantes dores de cabeça e insônia, especialmente nos primeiros anos do empreendimento, é outra lacuna que pesquisas futuras poderiam desenvolver.

Agradecimentos

-CAPES-PVE/BRASIL, “Impactos da Energia Eólica no Litoral do Nordeste: perspectivas para a construção de uma visão integrada da produção de energia 'limpa' no Brasil" (Processo 88881.068108/2014-01);

- CAPES-PGPSE/BRASIL, "Sistemas Ambientais costeiros e ocupação econômica do Nordeste" (Processo 88887.123947/2016-00); - PRONEM/CAPES/FUNCAP, "Análise socioambiental da implantação de parques eólicos no Nordeste: perspectivas para a sustentabilidade da geração de energia renovável no Brasil" (Processo PNE-0112-00068.01.00/16). 
Referências

ASSOCIAÇÃO BRASILEIRA DE ENERGIA EÓLICA (ABEEólica). Boletim Annual de Geração Eólica. São Paulo: ABEEólica, 2017.

AGÊNCIA NACIONAL DE ENERGIA ELÉTRICA (ANEEL). Sistema de Informações Georreferenciadas do Setor Elétrico (SIGEL). Disponível em: <http://sigel.aneel.gov.br/>. Acesso em: 29 mar. 2018.

AMARANTE, O. A. C.; BROWER, M.; ZACK, J. Atlas do Potencial Eólico Brasileiro.Rio de Janeiro: Ministério de Minas e Energia, 2001.

AQUILA, G., E. O.; PAMPLONA, A. R. Q.; ROTELA JUNIOR, P; FONSECA, M. N. An overview of incentive policies for the expansion of renewable energy generation in electricity power systems and the Brazilian experience. Renewable and Sustainable Energy Reviews, v. 70, p. 1090-1098, 2017.

ARAÚJO, J. C. H. As tramas da implementação da energia eólica na zona costeira do Ceará: Legitimação e contestação da "energia limpa". Mestrado em Planejamento Urbano e Regional. Rio de Janeiro: Universidade Federal do Rio de Janeiro, 2015.

ARAÚJO, M. S. M.; FREITAS, M. A. V. Acceptance of renewable energy innovation in Brazil--case study of wind energy. Renewable and Sustainable Energy Reviews v. 12, p. 584-91, 2008.

BAKA, J. Making space for energy: Wasteland development, enclosures, and energy dispossessions. Antipode, v.49, p. 977-996, 2016.

BELL, D.; GRAY, T.; HAGGETT, C. The 'Social Gap' in Wind Farm Siting Decisions: Explanations and Policy Responses. Enviromental Politics, v. 14, p. 460- 477, 2005.

BELL, D.; GRAY, T.; HAGGETT, C.; SWAFFIELD, J. Re-visiting the 'social gap': Public opinion and relations of power in the local politics of wind energy. Environmental Politics, v. 22, p. 115-135, 2013.

BIER; Lucile Lopes. Estudo da Paisagem: Percepções sobre o Complexo Eólico de Osório/ RS. 131 p. Dissertação (Mestrado) - Programa de Pós-Graduação em Geografia, Universidade Federal do Rio Grande do Sul, Porto Alegre, 2016.

BRANNSTROM, C.; GORAYEB, A.; MENDES, J. S.; LOUREIRO, C. V.; MEIRELES, A. J. A.; SILVA, E. V.; FREITAS, A. L. R.; OLIVEIRA, R. F. Is Brazilian wind power development sustainable? Insights from a review of conflicts in Ceará state. Renewable and Sustainable Energy Reviews, v. 67, p. 62-71, 2017.

BROWN, K. B. Wind power in northeastern Brazil: Local burdens, regional benefits and growing opposition. Climate and Development, v. 3, p. 344-60, 2011.

CARVALHO, R. G.; SILVA, A. L. B. Desafios da gestão da zona costeira no Brasil. In: CARVALHO, R. G.; PIMENTA, M. R. C. Gestão da Zona Costeira: Estudos de Casos no Nordeste do Brasil. Mossoró: Edições UERN, 2015, p. 8-12. 
CHAVES, L. O.; BRANNSTROM, C.; SILVA, E. V. Energia eólica e a criação de conflitos: Ocupação dos espaços de lazer em uma comunidade no nordeste do Brasil. Revista Sociedade e Território, v. 29, p. 49-69, 2017.

DE JONG, P.; DARGAVILle, R.; SILVER, J.; UTEMBE, S.; KIPERSTOK, A.; TORRES, E. A. Forecasting high proportions of wind energy supplying the Brazilian Northeast electricity grid. Applied Energy, v. 195, p. 538-555, 2017.

DE JONG, P.; KIPERSTOK, A.; SÁNCHEZ, A. S.; DARGAVILLE, R.; TORRES, E. A. Integrating large scale wind power into the electricity grid in the Northeast of Brazil. Energy, v. 100, p. 401-415, 2016.

DE JONG, P.; KIPERSTOK, A.; TORRES, E. A. Economic and environmental analysis of electricity generation technologies in Brazil. Renewable and Sustainable Energy Reviews, v. 52, p. 725-739, 2015.

FAIRHEAD, J.; LEACH, M.; SCOONES, I. Green grabbing: A new appropriation of nature? Journal of Peasant Studies, v. 39, n. 2, p. 237-261, 2012.

FARIAS, T. M. Afetividade e resistência: vínculo, transformações socioambientais e oposição capital-lugar na cidade de Galinhos-RN. 367p. Tese (Doutorado) - Programa de PósGraduação em Psicologia, Universidade Federal do Rio Grande do Norte, Natal, 2017.

FAST, S.; MABEE, W.; BAXTER, J.; CHRISTIDIS, T.; DRIVER, L.; HILL, S.; MCMURTY, J. J.; TOMKOW, M. Lessons learned from Ontario wind energy disputes. Nature Energy, v. 1, p. 1- 7, 2016.

FILGUEIRAS, A.; SILVA, T. M. V. Wind energy in Brazil--present and future. Renewable and Sustainable Energy Reviews, v. 7, p. 439-451, 2003.

GORAYEB, A.; BRANNSTROM, C. Caminhos para uma gestão participativa dos recursos energéticos de matriz renovável (parques eólicos) no nordeste do Brasil. Revista Mercator, v. 15, p. 101-115, 2016.

GORAYEB, A.; BRANNSTROM, C.; MENDES, J. S.; MEIRELES, A. J. A. Wind power gone bad: Critiquing wind power planning processes in northeastern Brazil. Energy Research and Social Science, v. 40, p. 82-88, 2018.

GORAYEB, A.; MENDES, J. S.; MEIRELES, A. J. A.; BRANNSTROM, C.; SILVA, E. V.; FREITAS, A. L. R. Wind-energy development causes social impacts in coastal Ceará state, Brazil: The case of the Xavier community. Journal of Coastal Research, v. 75, p. 383-387, 2016.

GORAYEB, A.; MEIRELES, A. J. A.; SILVA, E. V (Org.). Princípios básicos de Cartografia e Construção de Mapas Sociais: metodologías aplicadas ao mapeamento participativo. Fortaleza: Expressão Gráfica, 2015.

GWEC. Global Wind Report: Annual Market Update 2016. Brussels: Global Wind Energy Council, 2017.

HARVEY, D. O Novo imperialismo. Edições Loyola, 2003.

HARVEY, N.; DEW, R. E. C. Coastal impact of onshore wind farms in Australia. Journal of Coastal Research, v. 75, p. 992-996, 2016. 
HARVEY, N.; DEW, R. E. C.; HENDER, S. Rapid land use change by coastal wind farm development: Australian policies, politics and planning. Land Use Policy, v. 61, p. 368-378, 2017.

JABLONSKI, S.; FILET, M. Coastal management in Brazil - A political riddle. Ocean \& Coastal Management, v. 51, p. 536-543, 2008.

JUÁREZ, A. A.; ARAÚJO, A. M.; ROHATGI, J. S.; OLIVEIRA FILHO, O. D. Q. Development of the wind power in Brazil; Political, social, and technical issues. Renewable and Sustainable Energy Reviews, v. 39, p. 828-34, 2014.

LEROY, J. P., MEIRELES, J. Povos indígenas e comunidades tradicionais: Os visados territórios dos invisíveis. In: PORTO, M. F.; PACHECO, T.; LEROY, J. P. Injustiça ambiental e saúde no Brasil: O mapa de conflitos. Rio de Janeiro: Editora FIOCRUZ, 2013, p. 115-131.

LU, X.; MCELROY, M. B.; KIVILUOMA, J. Global potential for wind-generated electricity. Proceedings of the National Academies of Science, v. 109, p. 10933-10938, 2009.

MARRONI, E. V.; ASMUS, M. L. Historical antecedents and local governance in the process of public policies building for coastal zone of Brazil. Ocean \& Coastal Management, v.7 6, p. 30-37, 2013.

MCCARTHY, J.; THATCHER, J. Visualizing new political ecologies: A critical data studies analysis of the World Bank's renewable energy resource mapping initiative. Geoforum. No prelo.

MEIRELES, A. J. A. Danos socioambientais originados pelas usinas eólicas nos campos de dunas no Nordeste brasileiro e critérios para definição de alternativas locacionais. Confins, v. 11, online, 2011.

MEIRELES, A. J. A.; GORAYEB, A.; LIMA, G. S.; SILVA, D. R. F. S. Impactos socioambientais da energia eólica no litoral cearense. In: CORREIA, L. J. A.; OLIVEIRA, V. P. V.; MAIA, J. A. Evolução das paisagens e ordenamento territorial de ambientes interioranos e litorâneos. Fortaleza: Expressão Gráfica e Editora, 2015. p. 159-69.

MEIRELES, A. J. A.; GORAYEB, A.; SILVA, D. R. F. S.; LIMA, G. S. Socio-environmental impacts of wind farms on the traditional communities of the western coast of Ceará, in the Brazilian northeast. Journal of Coastal Research, v. 65, p. 81-86, 2013.

MORAES, A. C. R. Contribuições para a gestão da zona costeira do Brasil: Elementos para uma geografia do litoral brasileiro. São Paulo: Editora Hucitec, EDUSP, 1999.

PASQUALETTI, M. J. Opposing Wind Energy Landscapes: A Search for Common Cause. Annals of the Association of American Geographers, v. 101, p. 907-917, 2011.

QUEIROZ, L.; ROSSI, S.; MEIRELES, J.; COELHO, C. Shrimp aquaculture in the federal state of Ceará, 1970-2012: Trends after mangrove forest privatization in Brazil. Ocean \& Coastal Management, v. 73, p. 54-62, 2013.

RAND, J.; HOEN, B. Thirty years of North American wind energy acceptance research: What have we learned? Energy Research and Social Science, v. 29, p. 135-148, 2017.

SCHEIDEL, A.; SORMAN, A. H. Energy transitions and the global land rush: Ultimate drivers and persistent consequences. Global Environmental Change, v. 22, p. 588-595, 2012. 
SERVIÇO GEOLÓGICO DO BRASIL (CPRM). Projeto Batimetria. Disponível em: $<$ http://www.cprm.gov.br/publique/Geologia/Geologia-Marinha/Projeto-Batimetria3224.html>. Acesso em: 29 mar. 2018.

SILVA, R. C.; MARCHI NETO, I.; SEIFERT, S. S. Electricity supply security and the future role of renewable energy sources in Brazil. Renewable and Sustainable Energy Reviews, v. 59, p. 328-341, 2016.

SOVACOOL, B. K. Rejecting renewables: The socio-technical impediments to renewable electricity in the United States. Energy Policy, v. 37, p. 4500-4513, 2009.

SOVACOOL, B. K.; RATAN, P. L. Conceptualizing the acceptance of wind and solar energy. Renewable and Sustainable Energy Reviews, v. 16, p. 5268-5279, 2012.

WALKER, C.; BAXTER, J. Procedural justice in Canadian wind energy development: A comparison of community-based and technocratic siting processes. Energy Research and Social Science, v. 29, p. 160-169, 2017. 